\title{
Osmotically inactive volume, hydraulic conductivity, and permeability to dimethyl sulphoxide of human mature oocytes
}

\author{
H. Newton ${ }^{1}$, D. E. Pegg ${ }^{2}$, R. Barrass ${ }^{1}$ and R. G. Gosden ${ }^{1 *}$ \\ ${ }^{2}$ Centre for Reproduction, Growth and Development, School of Clinical Medicine, University of Leeds, Clarendon Wing (D floor), LGI, \\ Leeds, LS2 9NS; and ${ }^{2}$ Medical Cryobiology Unit, Biology Department, University of York, Heslington, York
}

\begin{abstract}
Controlled ovarian stimulation during an in vitro fertilization cycle usually produces large numbers of oocytes and, consequently, it is likely that more embryos will be generated than can be transferred in a given cycle. It is desirable to freeze-bank surplus oocytes before insemination to avoid the ethical and legal complications of disposing of or storing embryos. Although many attempts have been made to cryopreserve human oocytes, to date, post-thaw survival has been poor, and viable pregnancies after in vitro fertilization have been rare. A possible explanation for the lack of success is that the freezing methods have been adapted from animal studies but have not been optimized for the human oocyte. In this study, video microscopy was used to determine the volumetric responses of mature human oocytes to changes in osmolarity during preparation for freezing. A Boyle van't Hoff plot of data collected in static experiments with fresh human oocytes gave a value of $0.19 \pm 0.01$ (mean \pm SEM) for the osmotically inactive volume. Dynamic measurements during exposure to dimethyl sulphoxide at room temperature $\left(22^{\circ} \mathrm{C}\right)$ were analysed by a two-parameter transport model and

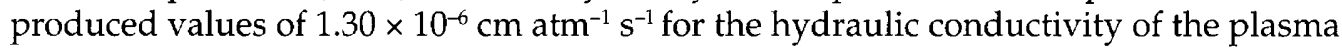
membrane and $3.15 \times 10^{-5} \mathrm{~cm} \mathrm{~s}^{-1}$ for dimethyl sulphoxide permeability (chi-squared = $0.43, \mathrm{df}=20$ ) of fresh human oocytes. Oocytes that had failed to fertilize had a slightly lower hydraulic conductivity and dimethyl sulphoxide permeability and, after exposure to $1.5 \mathrm{~mol}$ dimethyl sulphoxide $l^{-1}$, these cells appeared to become permeable to normally impermeable solutes. These permeability properties have been used to design a protocol for the addition and removal of dimethyl sulphoxide to control the magnitude of volumetric changes.
\end{abstract}

\section{Introduction}

During routine in vitro fertilization treatment (IVF) the ovaries undergo controlled ovarian stimulation to induce the growth of many antral follicles, which can be aspirated to retrieve mature oocytes. After fertilization, more than one embryo is normally replaced in the uterus to increase the chance of conceiving. Any surplus embryos of good quality are usually cryopreserved so that, if the transfer fails, they can be thawed for a further pregnancy attempt without the need for another round of ovarian stimulation. This strategy is successful (Marcus et al., 1997) but the creation of embryo banks raises many complex ethical and legal considerations, including the fate of orphaned embryos and the time limit set by regulatory authorities for storage (Trounson and Dawson, 1996). Successful oocyte cryopreservation would avoid these problems and make economical use of oocytes obtained in each cycle. The technique could also facilitate egg donation cycles and might be used to preserve oocytes in patients

${ }^{*}$ Correspondence.

Revised manuscript received 19 February 1999 before they undergo chemo- or radiotherapy (Apperley and Reddy, 1995), although the emergency nature of cancer treatment may preclude this strategy.

Numerous attempts have been made to freeze-thaw human oocytes but success rates have been disappointing because frozen-thawed oocytes are susceptible to zona hardening, cytoskeletal injury and abnormal meiotic divisions (Oktay et al., 1998). Evidently, the protocols that have been used in cryopreservation are still not optimal for this cell type and the biophysical properties determining the response of human oocytes to osmotic stress during freezing and thawing require investigation. Before cryopreservation, cells are equilibrated with a cryoprotective agent (CPA) to limit the extent of ice formation, but the solutions are hyperosmotic and CPAs penetrate cells more slowly than water. As a consequence, shrinkage occurs initially, as water is withdrawn down the osmotic gradient, and then there is a return to normal volume as the CPA penetrates the cell. During the subsequent process of freezing, ice forms preferentially outside the cell, concentrating extracellular solutes and again exposing the cell to hypertonic conditions (Mazur, 1963). While rapid cooling puts the cell at risk of Downloaded from Bioscientifica.com at 04/26/2023 09:37:09AM 
lethal intracellular freezing, an excessively slow rate of cooling overexposes the cell to the dangers of hypertonic conditions. Finally, when the cell is returned to isotonic solution after thawing, there is an inward osmotic flux and the possibility of excessive swelling and lysis of the oocyte. Thus, the permeabilities of the cell membrane to both water and CPA are important factors in determining optimum cooling rates.

The volume changes that occur during freezing and thawing can be calculated if the total surface area, volume and osmotically inactive volume of the cell are known, together with the permeability parameters of the oocyte plasma membrane to water and the CPA. In the present study, the osmotic responses of human oocytes to a range of non-isotonic solutions of impermeant solutes was measured by microscopy. These measurements were used to construct a Boyle van't Hoff plot, from which the non-osmotic volume $\left(V_{\mathrm{b}}\right)$ was derived. Video microscopy was used to record the time course of the volumetric responses during exposure of oocytes to the CPA, dimethyl sulphoxide (DMSO) at $1.5 \mathrm{~mol}$ $\mathrm{l}^{-1}$, which is a concentration widely used in cryopreservation. The dynamic data were analysed by a two-parameter model to yield values for the hydraulic conductivity $\left(L_{\mathrm{p}}\right)$ and solute permeability $\left(P_{s}\right)$. These parameters have been used to propose a method for the controlled addition and removal of CPA to and from oocytes that will reduce the risk of harmful swelling.

\section{Materials and Methods}

\section{Mature oocyte collection}

All oocytes were donated by patients who had given consent to the use of their oocytes for research which had been approved by the local ethics committee of the Leeds Teaching Hospitals NHS Trust. Fresh human oocytes at metaphase II were analysed within $2 \mathrm{~h}$ of follicular aspiration after downregulation with a GnRH analogue and stimulation using exogenous gonadotrophins (MacNamee and Brinsden, 1992). Oocytes that had failed to fertilize (FTF) were collected after $24-48 \mathrm{~h}$ in culture and those that were morphologically normal, spherical and with a polar body were selected for study. Before exposure to non-isotonic solutions, each oocyte was incubated in Leibovitz L-15 medium containing $1 \mathrm{mmol}$ ethylenediaminetetra acetic acid $\mathrm{l}^{-1}$ (EDTA) for $10 \mathrm{~min}$ at $37^{\circ} \mathrm{C}$ to ensure uniform spherical shrinkage (Younis et al., 1996).

\section{Determination of the osmotically inactive volume $\left(V_{b}\right)$ of human oocytes}

Hypertonic and hypotonic solutions were prepared by the addition of sucrose or pure water to Leibovitz-L15 medium (320 mosmol $\mathrm{kg}^{-1}$ ). The osmolality of each solution was adjusted using a freezing point osmometer (Advanced Instruments Ltd) to 230, 600, 1000 and 1400 mosmol $\mathrm{kg}^{-1}$, respectively. Individual oocytes were transferred to isotonic medium at room temperature $\left(22^{\circ} \mathrm{C}\right)$ with siliconized mouth pipettes, and the diameters were measured under an inverted microscope with a calibrated micrometer $(n=8)$. The individual oocytes were then pipetted into $70 \mu \mathrm{l}$ droplets of hypertonic or hypotonic solution in a humidified vessel to prevent evaporation. The cells were left to equilibrate for $5 \mathrm{~min}$ at room temperature before the new diameters were measured. Cell volume was calculated before and after exposure to non-isotonic solution, assuming spherical shrinkage. The volumes relative to the initial volume in isotonic medium were plotted against the reciprocal of osmolality. The data were fitted to a straight line by the leastsquares method and extrapolated to determine the cell volume in an infinitely concentrated solution (Toner et al., 1990).

\section{Calculation of the permeability parameters of human oocytes}

Solutions of $1.5 \mathrm{~mol}$ dimethyl sulphoxide $\mathrm{l}^{-1}$ (DMSO) and 1.5 mol DMSO ${ }^{-1}$ plus $0.1 \mathrm{~mol}$ sucrose $~^{-1}$ were prepared in Leibovitz-L15 medium and sterilized by filtration. A flow chamber was assembled on the stage of an inverted microscope with Hoffman optics (Nikon, Kingston-onThames) to visualize the dynamic response of oocytes to these non-isotonic solutions. The chamber consisted of a channel $0.5 \mathrm{~cm}$ wide and $4 \mathrm{~cm}$ long with a slight elevation at one end to aid unidirectional flow. A peristaltic pump delivered bathing solution to the elevated end of the chamber at a rate of $0.4 \mathrm{ml} \mathrm{min}^{-1}$. Video recording apparatus attached to the inverted microscope continuously recorded, at a magnification of $\times 400$, the volumetric response of the oocytes. Individual oocytes were transferred to the flow chamber and maintained in a static position with a holding pipette controlled by a micromanipulator (Narishige). The chamber was then perfused sequentially with (a) isotonic

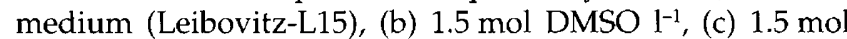
DMSO $1^{-1}$ plus 0.1 mol sucrose $1^{-1}$ and (d) isotonic medium again. The oocytes were exposed to each treatment for 1, 10, 10 and $5 \mathrm{~min}$, respectively, at room temperature. Before repeating the experiment on a new oocyte, the chamber was flushed with fresh medium to remove any residual DMSO or sucrose. The experiment was performed on eight fresh oocytes and 12 FTF oocytes.

The video recording was analysed on a PC using frame grabber apparatus (DT55 vision EZ frame grabber card). Frames were paused every $30 \mathrm{~s}$ and the cross-sectional area of the oocyte was measured using a computer graphics package (Global Lab Image Software). Cell volume was calculated from these values and converted into a volume relative to that in isotonic medium. The data were pooled to calculate the mean relative volume, at each $30 \mathrm{~s}$ time point, for both fresh and FTF oocytes. The volumes measured during the first $10 \mathrm{~min}$ were fitted to a two-parameter model defined by the following equations (Kleinhans, 1998):

$$
\begin{gathered}
J v_{\mathrm{w}}=-L_{\mathrm{p}}\left(\pi^{\mathrm{e}}-\pi^{\mathrm{i}}\right) \\
J v_{\mathrm{s}}=V_{\mathrm{s}} \times P_{\mathrm{s}}\left(C^{\mathrm{e}}-C^{\mathrm{i}}\right)
\end{gathered}
$$

where $J v_{\mathrm{w}}=$ volumetric water flux; $L_{\mathrm{p}}=$ hydraulic conductivity; $\pi^{\mathrm{e}}$ and $\pi^{\mathrm{i}}=$ external and internal osmolality, Downloaded from Bioscientifica.com at 04/26/2023 09:37:09AM 
respectively, assuming non-ideal behaviour of the intracellular solutes as described by Pegg et al. (1987) and Arnaud and Pegg (1990); $J v_{\mathrm{s}}=$ volumetric flux of DMSO; $P_{\mathrm{s}}=\mathrm{DMSO}$ permeability; $\mathrm{C}^{\mathrm{e}}$ and $\mathrm{C}^{\mathrm{i}}=$ external and internal concentrations of DMSO, respectively; and $V_{\mathrm{s}}=$ partial molar volume of DMSO. In accordance with Kedem and Katchalsky (1958), solute concentration was expressed in mol $\mathrm{l}^{-1}$. $V_{\mathrm{s}}$ was calculated by dividing the molecular weight of DMSO (78.13) by the density of DMSO at $20^{\circ} \mathrm{C}\left(1.1014 \mathrm{~g} \mathrm{~cm}^{-3}\right)$ giving the result: $71 \mathrm{~cm}^{3}$. No correction was made for change in density with temperature. Integration was performed using a simple forward integration scheme with time-step control implemented in a purpose-written PASCAL program running on a standard $\mathrm{PC}$. A weighted least squares best fit was obtained by iteration to minimize the chi-squared statistic described below.

\section{Statistical analysis}

Means \pm SD were calculated for each volume measurement. The Boyle van't Hoff regression was calculated by the method of least squares. The goodness of fit to the DMSO permeation data was quantified by calculating a chi-squared $\left(\chi^{2}\right)$ statistic using the following equation:

$$
\chi^{2}=\sum\left\{\left(V_{\text {obs }}-V_{\text {pred }}\right) / \sigma\right\}^{2}
$$

where $V_{\text {obs }}$ and $V_{\text {pred }}$ are the observed mean and predicted volume, respectively, at each data point and $\sigma^{2}$ is the variance associated with the experimental determination of each mean volume. The degrees of freedom are $n-2$. This approach follows that described by Walcerz et al. (1995).

\section{Results}

\section{Osmotically inactive volume of human oocytes}

Mature oocytes closely follow a Boyle van't Hoff relationship and thus exhibit an ideal osmometric response over the range $230-1400$ mosmol kg-1 (Fig. 1). Extrapolation of the data to infinite osmolality gave an osmotically inactive volume of $0.19 \pm 0.01$ (mean \pm SEM).

\section{Permeability parameters for human oocytes}

The exposure of oocytes to EDTA before exposure to nonisotonic solutions resulted in uniform spherical shrinkage which permitted the calculation of cell volume from measurements of cross-sectional area (Fig. 2a-d). The mean volumetric change of the oocytes during exposure to the cryoprotective media at each $30 \mathrm{~s}$ time point was calculated by pooling the data from each of the eight fresh oocytes. These data were plotted together with the standard error (Fig. 3).

A number of assumptions concerning the basic cell parameters were made to analyse the data. The measured diameters in the study ranged from 100 to $150 \mu \mathrm{m}$. The mean

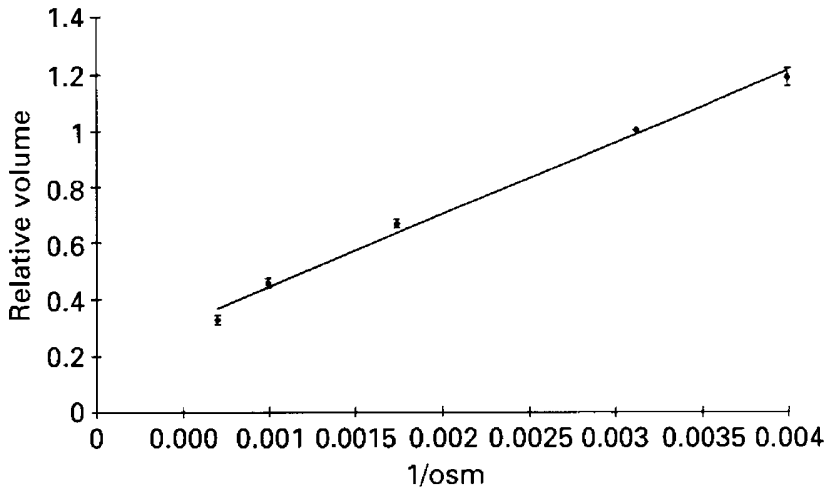

Fig. 1. Boyle van't Hoff plot of the osmotically inactive volume of mature human oocytes $(n=8)$.

radius of the vitellus in isotonic solution $(63 \mu \mathrm{m})$ gave a normal oocyte volume of $1.0 \times 10^{-6} \mathrm{~cm}^{3}$. The physiological water content was assumed to be $800 \mathrm{pl}\left(8 \times 10^{-7} \mathrm{~cm}^{3}\right)$ (B. J. Fuller, personal communication). Since the Boyle van't Hoff plot indicated that $81 \%$ of the cell volume was osmotically active, it was assumed that the cells contained insignificant amounts of osmotically inactive water. The measured osmolality of the Leibovitz medium was 320 mosmol kg-1 and the inclusion of $0.1 \mathrm{~mol}$ sucrose $1^{-1}$ raised it to 436 mosmol kg-1. These concentrations of impermeant solute were assumed for the relevant stages of the experiment.

The data obtained from the oocytes during the first $10 \mathrm{~min}$ of exposure to $1.5 \mathrm{~mol}$ DMSO $\mathrm{l}^{-1}$, using the assumed parameters, were modelled to give a best fit curve (Fig. 4), which shows that the oocytes shrink to approximately $60 \%$ of their isotonic volume within the first $50 \mathrm{~s}$ of exposure to cryoprotective media, as cellular water is withdrawn by the osmotic gradient. The cell then starts to re-expand as DMSO diffuses across the membrane. After $10 \mathrm{~min}$ of exposure to $1.5 \mathrm{~mol} \mathrm{DMSO}^{-1}$, the oocyte volume is approximately $90 \%$ of that in isotonic solution. FTF oocytes were slightly less permeable to DMSO (Fig. 5). The permeability properties of human oocytes were calculated from the model (Table 1).

The response to the complete sequence of solution changes using these values is shown (Fig. 6) with the line of best fit to the fresh oocyte data. The fit was good in stages 1 and 2 (when the oocytes were incubated in $1.5 \mathrm{~mol} \mathrm{DMSO} \mathrm{l}^{-1}$ in Leibovitz medium and then transferred to a medium containing $1.5 \mathrm{~mol}$ DMSO $1^{-1}$ plus $0.1 \mathrm{~mol}$ sucrose $1^{-1}$ in Leibovitz medium). The observed pattern was modelled less well in stage 3 (when the oocytes were finally transferred to isotonic Leibovitz medium). The overall value of chi-squared was 2.60. The volume of FTF oocytes consistently exceeded that predicted during the second and third stages. The fit to the data collected from these oocytes could be obtained in stage 2 if a reduced transmembrane osmotic differential of impermeant solutes to $90 \%$ of the theoretical value was assumed. These findings indicate that these oocytes had become leaky to the Leibovitz salts.

In the present study, the one step addition of $1.5 \mathrm{~mol}$ Downloaded from Bioscientifica.com at 04/26/2023 09:37:09AM 

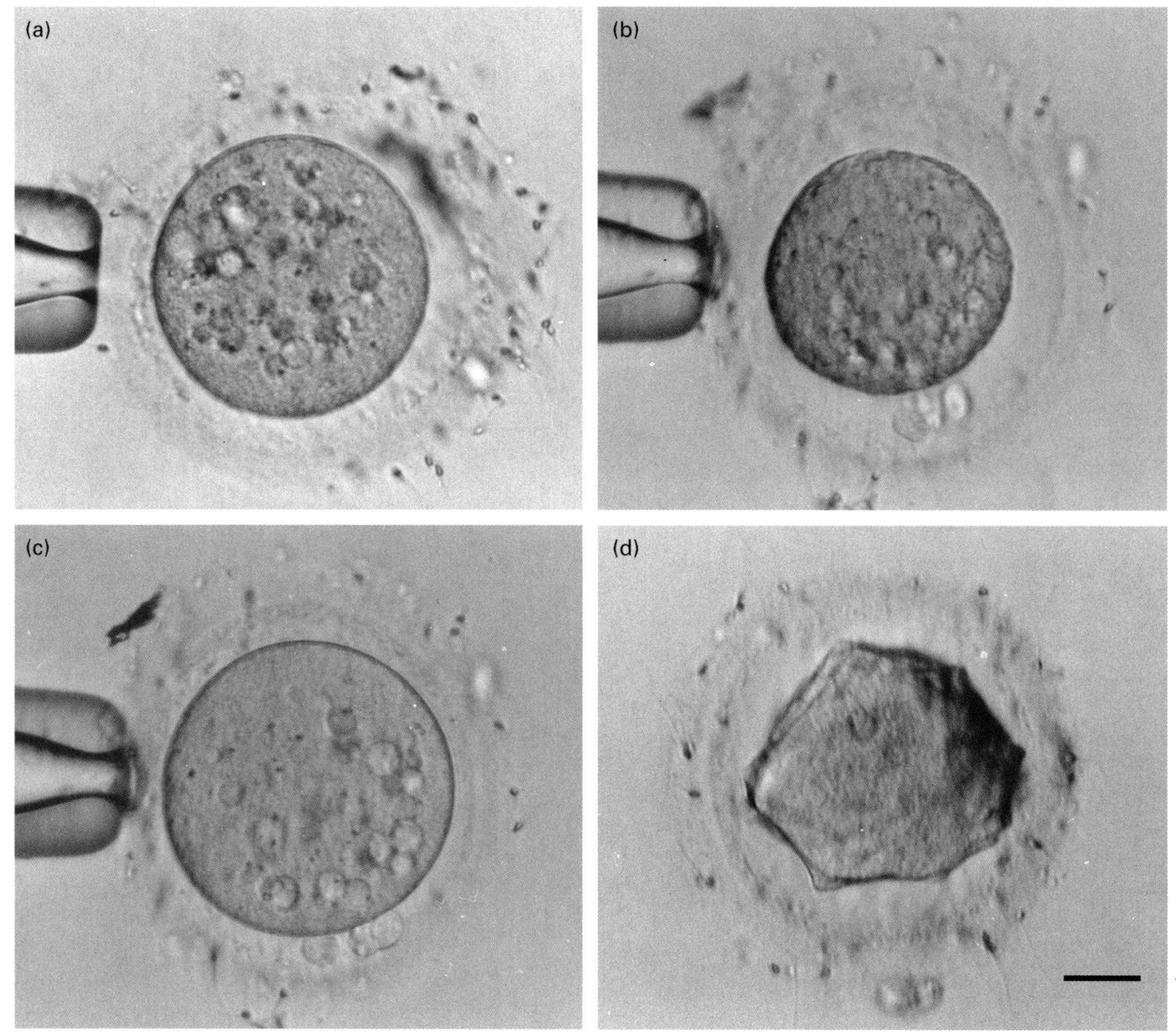

Fig. 2. The morphological appearance of mature human oocytes during exposure to isotonic and non-isotonic solution at room temperature. (a) A morphologically normal oocyte in isotonic Leibovitz medium. (b) A shrunken oocyte after exposure for $30 \mathrm{~s}$ to $1.5 \mathrm{~mol} \mathrm{DMSO} \mathrm{1-1}^{-1}$. (c) A swollen oocyte after sequential exposure to $1.5 \mathrm{~mol} \mathrm{DMSO} \mathrm{l-1}^{-1}, 1.5 \mathrm{~mol} \mathrm{DMSO}^{-1}$ supplemented with $0.1 \mathrm{~mol}$ sucrose $1^{-1}$ and reintroduction of isotonic Leibovitz solution. (d) An oocyte exposed to 1.5 mol

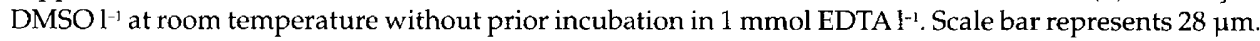

DMSO $1^{-1}$ caused a $40 \%$ decrease in cell volume, and the subsequent direct transfer to isotonic solution caused the oocytes to swell to $140-150 \%$ of the physiological volume. Values calculated for the biophysical properties of the oocytes have been used to produce a model that uses a two-step procedure for the addition and removal of cryoprotectant that limits volumetric changes to approximately $30 \%$ (Fig. 7).

\section{Discussion}

Many attempts have been made to cryopreserve mature human oocytes but, in general, post-thaw viability rates have been disappointing and the fertilization rates correspondingly poor (Mandelbaum et al., 1988). However, a few pregnancies and live births have been reported in humans (Chen, 1986; Van Uem et al., 1987; Porcu et al., 1997), cows (Fuku et al., 1992), rabbits (Al-Hasani et al., 1989) and mice

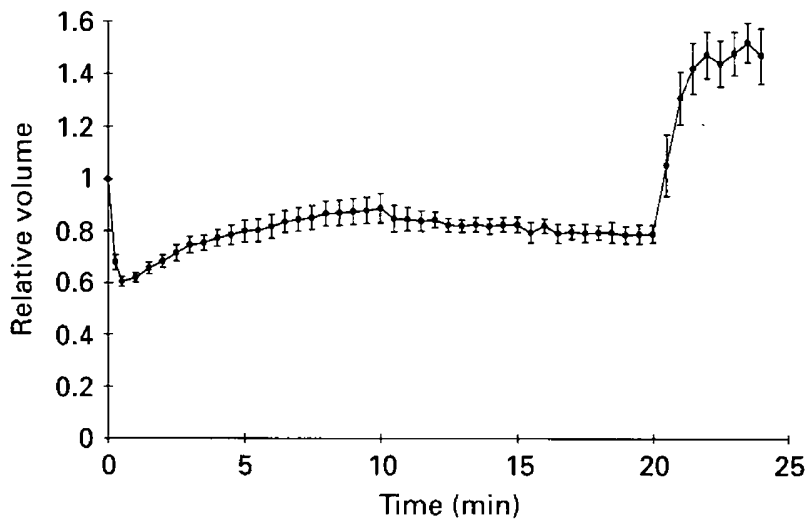

Fig. 3. Mean relative cell volumes at room temperature of fresh human mature oocytes. The oocytes were exposed during stage 1 $(0-10 \mathrm{~min})$ to $1.5 \mathrm{~mol} \mathrm{DMSO}^{-1}$, during stage $2(10-20 \mathrm{~min})$ to $1.5 \mathrm{~mol}$ DMSO ${ }^{-1}$ plus $0.1 \mathrm{~mol}$ sucrose $\mathrm{l}^{-1}$ and, during stage $3(20-25 \mathrm{~min})$, to isotonic Leibovitz solution $(n=8)$. 


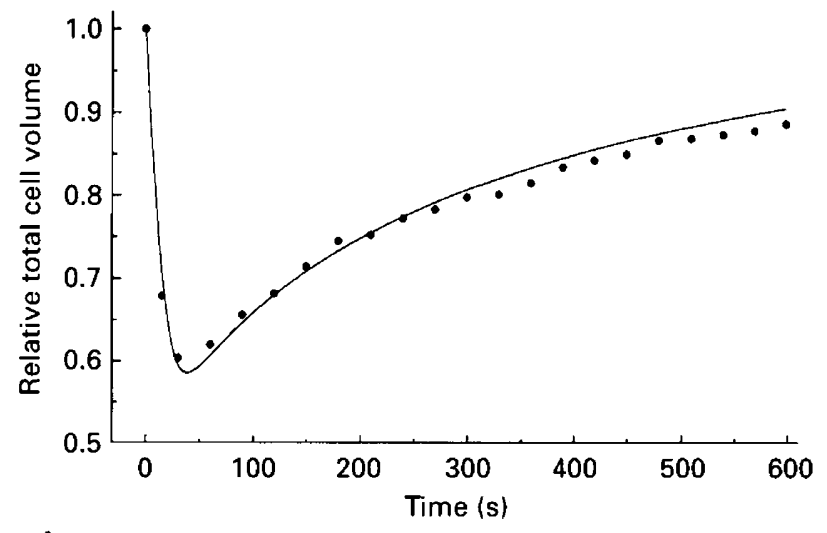

Fig. 4. The curve of best fit, using the two-parameter model, for data on the dynamic responses of the volume of freshly isolated human oocytes immersed in $1.5 \mathrm{~mol}$ DMSO $\mathrm{l}^{-1}$ in Leibovitz solution. The derived values of the permeability parameters are: hydraulic conductivity: $1.30 \times 10^{-6} \mathrm{~cm} \mathrm{~atm}^{-1} \mathrm{~s}^{-1}$; solute permeability for dimethyl sulphoxide: $3.15 \times 10^{-5} \mathrm{~cm} \mathrm{~s}^{-1}$. Chi-squared $=0.43$.

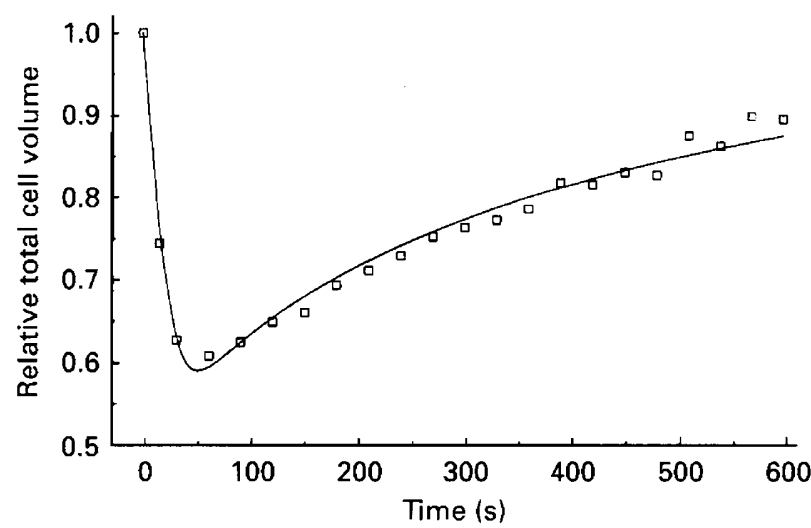

Fig. 5. The curve of best fit, using the two-parameter model, for data on the dynamic responses of the volume of failed to fertilize (FTF) human oocytes immersed in $1.5 \mathrm{~mol} \mathrm{DMSO}^{-1}$ in Leibovitz solution. The derived values of the permeability parameters are: hydraulic conductivity: $1.00 \times 10^{-6} \mathrm{~cm} \mathrm{~atm}^{-1} \mathrm{~s}^{-1}$; solute permeability for dimethyl sulphoxide: $2.50 \times 10^{-5} \mathrm{~cm} \mathrm{~s}^{-1}$. Chi-squared $=0.83$.

(Whittingham, 1977; Glenister et al., 1987), demonstrating that the technique is feasible. Mature oocytes are arrested at metaphase of the second meiotic division when the cell has a highly organized cytoskeletal system, numerous cytoplasmic organelles and a zona pellucida. Damage to any of these structures during freezing can reduce viability after thawing. The decrease in the rate of fertilization could be due to hardening of the zona pellucida (Wood et al., 1992; Carroll et al., 1993), and this hypothesis is supported by the better results obtained with intracytoplasmic sperm injection (ICSI) than with IVF (Gook et al., 1995; Kazem et al., 1995) and the creation of viable pregnancies (Porcu et al., 1997; Polak de Fried et al., 1998). Reports that both DMSO and cooling at temperatures well above $0^{\circ} \mathrm{C}$ may irreversibly damage the cytoskeleton in human oocytes (Johnson and Pickering, 1987; Pickering and Johnson, 1987; Van der Elst et al., 1988;
Table 1. Permeability properties of human oocytes calculated from a two-parameter transport model

\begin{tabular}{lcc}
\hline & Fresh oocytes & $\begin{array}{c}\text { Oocytes that had } \\
\text { failed to fertilize }\end{array}$ \\
\hline $\begin{array}{l}\text { Hydraulic conductivity } \\
\left(\mathrm{cm} \mathrm{atm}^{-1} \mathrm{~s}^{-1}\right)\end{array}$ & $1.30 \times 10^{-6}$ & $1.0 \times 10^{-6}$ \\
$\begin{array}{c}\text { Solute permeability for } \\
\text { dimethyl sulphoxide }\left(\mathrm{cm} \mathrm{s}^{-1}\right)\end{array}$ & $3.15 \times 10^{-5}$ & $2.5 \times 10^{-5}$ \\
Chi-squared $(\mathrm{df}=20)$ & 0.43 & 0.83 \\
\hline
\end{tabular}

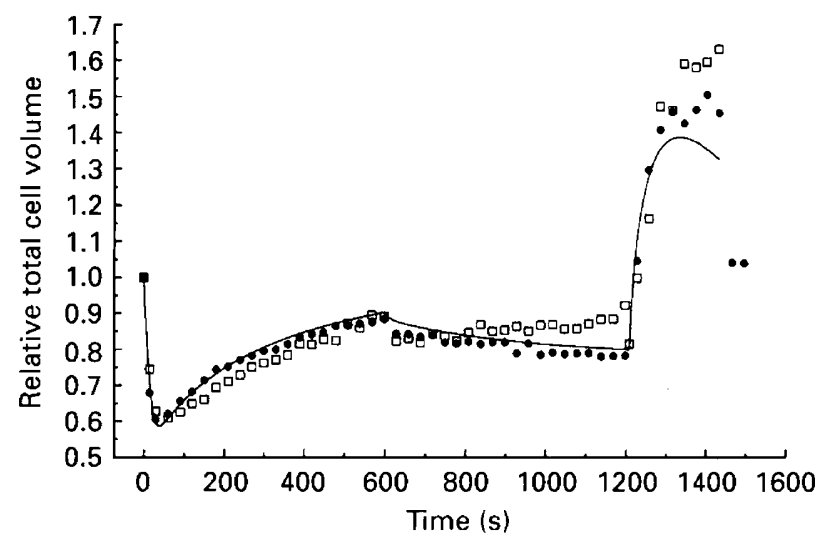

Fig. 6. Curve plotted for the entire experiment using the best-fit values from stage 1 fresh human oocyte data $(\mathbf{)}$ and failed to fertilize (FTF) oocyte data ( $\square$ ).

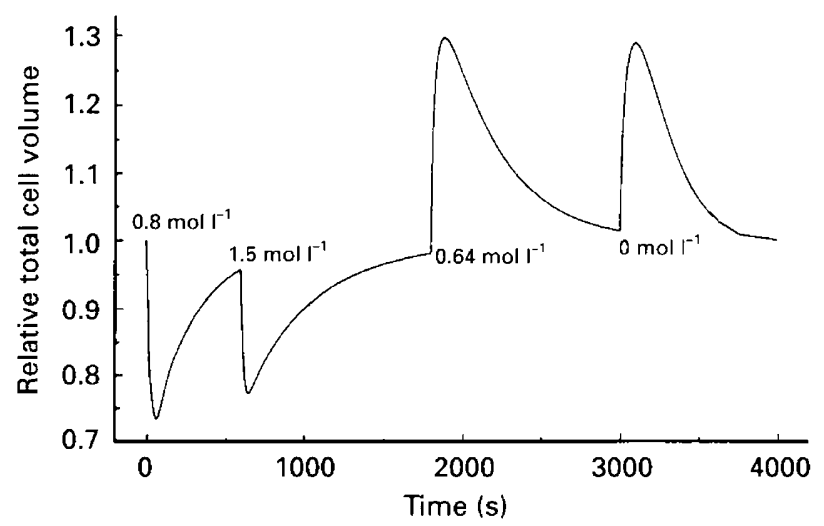

Fig. 7. Calculated osmotically induced excursions in cell volume when mature human oocytes are exposed in sequence to $0.8,1.5,0.64$ and $0 \mathrm{~mol} \mathrm{DMSO}^{-1}$ in isotonic media. This scheme would restrict volume changes to $\pm 30 \%$.

Pickering et al., 1990) are of greater concern.

Freezing protocols were derived originally from animal studies, but the size and structure of mature oocytes differ significantly among species. Therefore, extrapolation to the human oocyte is unsafe and studies inter alia of osmotic stress in these cells during the freezing procedure are required to design cryopreservation protocols.

The present results show that mature oocytes behave as 
ideal osmometers between 230 and 1400 mosmol kg-1 and indicate that the osmotically inactive volume is about 0.19 . Non-aqueous cellular material contributes a large component to this volume but it is not unusual for a proportion of the cellular water to be osmotically inactive too. However, in human oocytes, it seems that there is little non-osmotic water since approximately $80 \%$ of the cell volume is osmotically active. Reported measurements of the nonosmotic volume of mature oocytes in other species indicate that this may be a general phenomenon: $0.18-0.20$ for murine oocytes (Leibo, 1980; Toner et al., 1990; Hunter et al., 1992a); 0.1 for non-human primate oocytes (Younis et al., 1996); and 0.23-0.29 for human oocytes (Hunter et al., 1992a,b; McWilliams et al., 1995). This conclusion has important implications for the calculation of changes in cell volume during the addition and removal of cryoprotectants (Arnaud and Pegg, 1990).

Membrane permeability modelling is commonly used to derive parameters describing water and solute permeability from experimental measurements of changes in cell volume. The Kedem and Katchalsky (1958) formalism is most commonly used in such analyses. However, Kleinhans (1998) has emphasized that the underlying assumption that solute moves exclusively through the same channels as water is rarely secure. When this assumption is not justified, the derived parameters have no precise physical meaning, but merely describe the experimental curve in a more or less empirical way. Since it is highly improbable that this assumption is met by oocytes, the earlier and simpler twoparameter $\left(L_{\mathrm{p}}\right.$ and $\left.P_{\mathrm{s}}\right)$ formalism has been used in the present study. The resulting values of $L_{\mathrm{p}}$ and $P_{\mathrm{s}}$ describe the experimental data adequately and can be used to predict the effect of changing protocols for the addition and removal of cryoprotectants.

The curve of best fit was determined by minimizing the squares of the differences between the mean observations and the values predicted by the model, weighted by the variance associated with each data point. The value of the chi-squared statistic indicates the goodness-of-fit; in this case, with 20 degrees of freedom, the transitional value for $P$ $<0.05$ is 31.4 whereas, in the present study, chi-squared $=$ 0.43 (an extremely good fit). This approach cannot assign individual tolerances to the derived parameters and, indeed, Walcerz et al. (1995) have argued that the nonlinearity and asymmetry of the data preclude the use of standard methods to estimate the error associated with $L_{\mathrm{p}}$ and $P_{\mathrm{s}}$. In fact, it is unclear what value individual error measures would have, since $L_{\mathrm{p}}$ and $P_{\mathrm{s}}$ are used together to predict the complete curve, and it is the correspondence between that curve and the data that is important.

In the present study, a value of $1.30 \times 10^{-6} \mathrm{~cm} \mathrm{~atm}^{-1} \mathrm{~s}^{-1}$ was obtained for the hydraulic conductivity $\left(L_{\mathrm{p}}\right)$ of mature oocytes at room temperature in the presence of $1.5 \mathrm{~mol}$ $\mathrm{DMSO}^{-1}$. There is no general agreement over the units used for expressing $L_{\mathrm{p}}$ but, in SI units, the above value equates to $1.31 \times 10^{-13} \mathrm{~m}^{3} \mathrm{~N}^{-1} \mathrm{~s}^{-1}$. In another commonly used unit, the above result corresponds to $0.78 \mu \mathrm{m} \mathrm{atm}^{-1} \mathrm{~min}^{-1}$, which compares well with reported measurements in the same species: $\quad 0.40-0.70 \mu \mathrm{m} \mathrm{atm}{ }^{-1} \mathrm{~min}^{-1}$ and $0.64-0.84 \mu \mathrm{m} \mathrm{atm}^{-1}$ $\mathrm{min}^{-1}$ for human fresh and FTF oocytes, respectively
(Bernard et al., 1988; Hunter et al., 1992a,b; Paynter et al., 1997). Values are also in a similar range in other species: 0.36-0.77 $\mu \mathrm{m} \mathrm{atm}^{-1} \mathrm{~min}^{-1}$ for murine oocytes (Leibo, 1980; Bernard et al., 1988; Hunter et al., 1992a; Paynter et al., 1997; Pfaff et al., 1998) and $0.47 \mu \mathrm{m} \mathrm{atm}{ }^{-1} \mathrm{~min}^{-1}$ for bovine oocytes (Ruffing et al., 1993).

The solute permeability of the membrane to DMSO was estimated to be $3.15 \times 10^{-5} \mathrm{~cm} \mathrm{~s}^{-1}\left(0.315 \mu \mathrm{m} \mathrm{s}^{-1}\right)$, which is comparable with values obtained in previous studies of human and murine oocytes of $0.26 \mu \mathrm{m} \mathrm{s}^{-1}$ (Paynter et al., 1997) and 0.16-0.24 $\mu \mathrm{m} \mathrm{s}^{-1}$, respectively (Paynter $e t$ al., 1997). Studies that investigated the membrane permeability of oocytes to different CPAs reported values for propylene glycol of $0.82 \mu \mathrm{m} \mathrm{s}^{-1}$ and $0.31-0.48 \mu \mathrm{m} \mathrm{s}^{-1}$ in human and murine studies, respectively (Fuller et al., 1992). In contrast, the permeability of murine oocytes to glycerol is two orders of magnitude lower, at $0.002 \mu \mathrm{m} \mathrm{s}^{-1}$ (Jackowski et al., 1980).

A slightly lower water permeability $\left(1.0 \times 10^{-6} \mathrm{~cm} \mathrm{~atm}^{-1}\right.$ $\left.\mathrm{s}^{-1}\right)$ and solute permeability for DMSO $\left(2.5 \times 10^{-5} \mathrm{~cm} \mathrm{~s}^{-1}\right)$ (chisquared $=0.83$ ) was observed when FTF oocytes were compared with fresh oocytes. This result is in contrast to the measurements of hydraulic conductivity reported by Hunter et al (1992a), although these authors commented upon the extreme variation in their results. The most notable difference in the present study between fresh and FTF oocytes was in the apparent leakiness to normally impermeant salts after exposure to DMSO. It is unclear whether these permeability changes are connected with the inability of oocytes to be fertilized or are secondary to exposure to the conditions for IVF or to ageing in vitro. However, changes in the zona are unlikely to have been responsible since this is a highly permeable membrane.

The one-step addition of $1.5 \mathrm{~mol}$ DMSO $1^{-1}$ to oocytes produced an approximately $40 \%$ decrease in cell volume, and the subsequent direct transfer to isotonic solution caused the oocyte to swell to $140-150 \%$ of the original volume. It is not known whether such changes are harmful in themselves, but the permeability data determined in this study can be used to design methods that reduce osmotic stress to the oocyte. Indeed, a two-step procedure for the addition and removal of DMSO that limits volumetric changes to $\pm 30 \%$ has been established. This limit was based on the tolerance of other cell types and, if future research indicates that the margin is too generous, this model can be adapted easily for stricter limits. For a tolerance limit of $\pm 30 \%$, oocytes should at first be equilibrated with $0.8 \mathrm{~mol}$ DMSO $1^{-1}$ for about

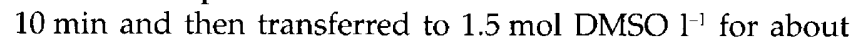
$20 \mathrm{~min}$ before freezing. After thawing, oocytes should be transferred to $0.64 \mathrm{~mol}^{\text {DMSO }} \mathrm{l}^{-1}$ for about $20 \mathrm{~min}$ before being returned to isotonic conditions. Stepwise changes in CPA exposure are already in common practice, but the present study has produced a theoretical basis and a quantitative indication of the expected impact on cell volume. Unfortunately, testing the practical benefits of this new protocol is likely to be slow because of the scarcity of fresh oocytes for research.

The authors gratefully acknowledge the co-operation of the staff and patients from the Assisted Conception Unit at Leeds General Infirmary for the donation of mature eggs. They are particularly Downloaded from Bioscientifica.com at 04/26/2023 09:37:09AM 
grateful to F. Kleinhans for extensive discussions concerning the analysis of volumetric data reported here. They would also like to thank K. Harrison for the use of the frame grabbing apparatus. This project was funded by a grant from the Leukaemia Research Fund.

\section{References}

Al-Hasani S, Kirsch J, Diedrich K, Blanke S, van der Van $\mathbf{H}$ and Krebs D (1989) Successful embryo transfer of cryopreserved and in vitro fertilised rabbit oocytes Human Reproduction 4 77-79

Apperley JF and Reddy N (1995) Mechanisms and management of treatment related gonadal failure in recipients of high dose chemoradiotherapy Btood Reviews 9 93-116

Arnaud FG and Pegg DE (1990) Permeation of glycerol and propane-1,2-diol into human platelets Cryobiology 27 107-118

Bernard A, McGrath J, Fuller BJ, Imoedemhe D and Shaw RW (1988) Osmotic response of oocytes using a microscope diffusion chamber: a preliminary study comparing murine and human ova Cryobiology 25 495-501

Carroll J, Wood MJ and Whittingham DG (1993) Normal fertilization and development of frozen thawed mouse oocytes: protective action of certain macromolecules Biology of Reproduction 48 606-612

Chen C (1986) Pregnancy after human oocyte cryopreservation Lancet 1 884-886

Fuku E, Kojima T, Shioya Y, Marcus GJ and Downey BR (1992) In vitro fertilisation and development of frozen-thawed bovine oocytes Cryobiology $29485-492$

Fuller BJ, Hunter JE, Bernard AG, McGrath JJ, Curtis P and Jackson A (1992) The permeability of unfertilised oocytes to 1,2 propanediol: a comparison of mouse and human cells Cryo-letters 13 287-290

Glenister PH, Wood MJ, Kirby C and Whittingham DG (1987) incidence of chromosome anomalies in first cleavage mouse embryos obtained from frozen-thawed oocytes fertilised in vitro. Gamete Research 16 205-216

Gook DA, Schiewe MC, Osborn SM, Asch RH, Jansen RP and Johnston WI (1995) Intracytoplasmic sperm injection and embryo development of human oocytes cryopreserved using 1,2-propanediol Human Reproduction $102637-2641$

Hunter JE, Bernard A, Fuller BJ, McGrath J and Shaw RW (1992a) Measurements of the membrane water permeability $\left(L_{\mathrm{p}}\right)$ and its temperature dependence (activation energy) in human fresh and failed-tofertilise oocytes and mouse oocytes Cryobiology 29 240-249

Hunter JE, Bernard A, Fuller B, McGrath J and Shaw RW (1992b) Plasma membrane water permeabilities of human oocytes: the temperature dependence of water movement in individual cells Journal of Cellular Physiology 150 175-179

Jackowski S, Leibo SP and Mazur P (1980) Glycerol permeabilities of fertilised and unfertilised mouse ova Journal of Experimental Zoology 212 329-341

Johnson MH and Pickering SJ (1987) The effect of dimethylsulphoxide on the microtubular system of the mouse oocyte Development 100313-324

Kazem R, Thompson LA, Srikantharajah A, Laing MA, Hamilton MPR and Templeton A (1995) Cryopreservation of human oocytes and fertilization by two techniques: in vitro fertilization and intracytoplasmic sperm injection Human Reproduction 10 2650-2654

Kedem $O$ and Katchalsky A (1958) Thermodynamic analysis of the permeability of biological membranes to non-electrolytes Biochimica Biophysica Acta $27229-246$

Kleinhans FW (1998) Membrane permeability modeling: Kedem-Katchalsky versus a two-parameter formalism Cryobiology 37 271-289

Leibo SP (1980) Water permeability and its activation energy of fertilised and unfertilised mouse ova Journal of Membrane Biology 53 179-188

MacNamee MC and Brinsden PR (1992) Superovulation strategies in assisted conception. In A Textbook of In Vitro Fertilization and Assisted Reproduction pp 111-125 Eds PR Brinsden and PA Rainsbury. Parthenon, Carnforth, Lancs
McWilliams RB, Gibbons WE and Leibo SP (1995) Osmotic and physiological responses of mouse zygotes and human oocytes to mono- and disaccharides Human Reproduction 10 1163-1171

Mandelbaum J, Junca AM, Plachot M, Alnot MO, Salat-Baroux J, Alvarez A, Tibi C, Cohen J, Debache C and Tesquier L (1988) Cryopreservation of human embryos and oocytes Human Reproduction 3 117-119

Marcus SF, Marcus NK, Avery SM, Macnamee MC and Brinsden PR (1997) Comparative analysis of pregnancies resulting from fresh versus cryopreserved-thawed embryo transfers Human Reproduction 12 (Abstract Book 1) 99

Mazur P (1963) Kinetics of water loss from cells at subzero temperatures and the likelihood of intracellular freezing Iournal of General Physiology 47 347-369

Oktay K, Newton H, Aubard Y, Salha O and Gosden RG (1998) Cryopreservation of immature human oocytes and ovarian tissue: an emerging technology? Fertility and Sterility 69 1-7

Paynter S, Cooper A, Gregory L and Fuller BJ (1997) A comparison of human and murine oocyte permeability to the cryoprotectant dimethylsulphoxide Journal of Reproduction and Fertility Abstract Series 19 Abstract 40

Pegg DE, Hunt CJ and Fong LP (1987) Osmotic properties of the rabbit corneal endothelium and their relevance to cryopreservation Cell Biophysics $\mathbf{1 0}$ 169-191

Pfaff RT, Liu J, Gao D, Peter AT, Li TK and Critser JK (1998) Water and DMSO membrane permeability characteristics of in vivo and in vitro derived and cultured murine oocytes and embryos Molecular Human Reproduction 4 $51-59$

Pickering SJ and Johnson MH (1987) The influence of cooling on the organisation of the meiotic spindle of the mouse oocyte Human Reproduction 2 207-216

Pickering SJ, Cant RM, Braude PR, Currie J and Johnson MH (1990) Transient cooling to room temperature can cause irreversible disruption of the meiotic spindle in the human oocyte Fertility and Sterility 54 102-108

Polak de Fried E, Notrica J, Rubinstein M, Marazzi A, Gonzalez MG (1998) Pregnancy after human donor oocyte cryopreservation and thawing in association with intracytoplasmic sperm injection in a patient with ovarian failure Fertility and Sterility $69555-557$

Porcu E, Fabbri R, Seracchioli R, Ciotti PM, Savelli L, Ghi T, Marsella T, Primavera MR and Flamigni $C$ (1997) Birth of a healthy female after intracytoplasmic sperm injection of cryopreserved human oocytes Fertility and Sterility 68 724-726

Ruffing NA, Steponkus PL, Pitt RE and Parks JE (1993) Osmometric behavior, hydraulic conductivity and incidence of intracellular ice formation in bovine oocytes at different developmental stages Cryobiology 30 562-580

Toner M, Cravalho EG and Armant DR (1990) Water transport and estimated transmembrane potential during freezing of mouse oocytes fournal of Membrane Biology 115 261-272

Trounson A and Dawson K (1996) Storage and disposal of embryos and gametes British Medical Journal 313 1-2

Van der Elst J, Van den Abbeel E, Jacobs R, Wisse E and Van Steirteghem A (1988) Effect of 1,2-propanediol and dimethylsulphoxide on the meiotic spindle of the mouse oocyte Human Reproduction 3960-967

Van Uem JFHM, Siebzehnrubl ER, Schuh B, Koch R, Trotnow S and Lang N (1987) Birth after cryopreservation of unfertilised oocytes Lancet 1 752-753

Walcerz DB, Taylor MJ and Busza AL (1995) Determination of the kinetics of permeation of dimethyl sulfoxide in isolated corneas Cell Biophysics 26 79-102

Whittingham DG (1977) Fertilisation in vitro and development to term of unfertilised mouse oocytes previously stored at $-196^{\circ} \mathrm{C}$ Journal of Reproduction and Fertility 49 89-94

Wood MJ, Whittingham DG and Sang-Ho L (1992) Fertilization failure of frozen mouse oocytes is not due to premature cortical granule release Biology of Reproduction 46 1187-1195

Younis AI, Toner M, Albertini DF and Biggers JD (1996) Cryobiology of nonhuman primate oocytes Human Reproduction 11 156-165 